\title{
Transcriptomic Response of In Vitro Potato (Solanum tuberosum L.) to Piezoelectric Ultrasound
}

\author{
Jaime A. Teixeira da Silva ${ }^{1,2} \cdot$ Norbert Hidvégi $^{1} \cdot$ Andrea Gulyás $^{1} \cdot$ Bianka Tóth ${ }^{3} \cdot$ Judit Dobránszki $^{1}$ \\ Published online: 29 February 2020 \\ (C) The Author(s) 2020
}

\begin{abstract}
As part of a wider project to assess the impact of ultrasound on in vitro plant growth, this paper aimed to determine whether the application of piezoelectric ultrasound (PE-US) would induce changes to the transcriptome of in vitro potato (Solanum tuberosum L.). After exposing explants (single-node segments with a single leaf) to PE-US ( $35 \mathrm{kHz} ; 70 \mathrm{~W})$ for $20 \mathrm{~min}$, the effect of this stressor was determined at $0 \mathrm{~h}, 24 \mathrm{~h}, 48 \mathrm{~h}, 1$ week, and 4 weeks to assess the possible immediate and residual effects of PE-US on the potato transcriptome. After mRNA was isolated, bioinformatic processing and analysis of RNA-seq datasets, KEGG analysis revealed that $24 \%$ of up-regulated biological processes were a response to stress immediately after the application of PE-US (reducing to $11 \%$ and $9 \%$ at $48 \mathrm{~h}$ and 4 weeks, respectively). After assessing a total of 40,430 genes for expression intensity at these five time intervals, it was found that $138,72,18,5$, and 59 differentially expressed genes (DEGs), respectively, were significantly up-regulated, while 6, 82, 96, 172, and 107 DEGs, respectively, were down-regulated. DEGs coding for universal stress protein, chitinase, catalase, zinc finger proteins, 21 transcription factors, glutathione $S$-transferase, and 17 heat shock proteins, mainly Hsp70, Hsp20, and Hsp90 proteins, and possibly the first of such discovery in US-based plant stress research, was detected. Following the validation of RNA-seq data by RTqPCR, between SeqMonk LFC and RT-qPCR LFC, the Spearman and Pearson correlation coefficients were 0.86 and 0.90, respectively. Plantlets exposed to PE-US had significantly shorter shoots but significantly longer roots as well as higher shoot and root fresh weight, while chl $b$ and total chl were significantly lower but the chl $a / b$ ratio was significantly higher in plantlets exposed to PE-US. PE-US thus constituted an acute abiotic stress, but by 4 weeks, in vitro potato plantlets managed to mitigate the stress through the production of antioxidant enzyme systems and other functional metabolic changes.
\end{abstract}

Keywords Abiotic stress - Chlorophyll · Differentially expressed genes · Enzymes · Heat shock proteins · Plant growth · RT-qPCR · Wounding

Key Message Piezoelectric ultrasound (PE-US) constitutes a nonfatal abiotic stress to in vitro potato. A notable discovery was the expression of 17 heat shock proteins in response to this abiotic stress.

Electronic supplementary material The online version of this article (https://doi.org/10.1007/s11105-020-01204-3) contains supplementary material, which is available to authorized users.

Judit Dobránszki

dobranszki@ freemail.hu

1 Research Institute of Nyíregyháza, Institutes for Agricultural Research and Educational Farm (IAREF), University of Debrecen, P.O. Box 12, Nyíregyháza H-4400, Hungary

2 Kagawa, Japan

3 Institutes for Agricultural Research and Educational Farm (IAREF), University of Debrecen, Böszörményi u. 138, Debrecen H-4032, Hungary

\section{Introduction}

When sound waves are applied to plants, either at a low frequency (from $20 \mathrm{~Hz}$ up to $20 \mathrm{kHz}$ ) or ultrasound (US) (>20 kHz), this can constitute an abiotic stress (Wang et al. 2006). Rokhina et al. (2009) described several detrimental effects in multiple in vitro plant species, following exposure to US, on cellular and nuclear integrity. The examination of dozens of studies that had applied acoustic sound or US to in vitro plants revealed that invariably extreme conditions (high frequencies or long exposure periods) were detrimental - even fatal - to plants, while milder conditions could either improve or negatively impact, depending on the plant species, growth, and/or development in vitro, including an effect on the antioxidant system, affecting RNA/DNA, ploidy, and hormone balance (Teixeira da Silva and Dobránszki 2014). As one example, in hazelnut (Corylus avellana L.), low frequency $(29 \mathrm{kHz})$ US stimulated the expression of genes coding for 
Table 1 Number of significantly up- and down-regulated differentially expressed genes (DEGs) (based on GO annotation in Blast2GO) at five time intervals during the growth of potato in vitro stem nodal sections following exposure to piezoelectric ultrasound (35 kHz; $70 \mathrm{~W} ; 20 \mathrm{~min}$ )

\begin{tabular}{lll}
\hline $\begin{array}{l}\text { Treatment } \\
\text { comparisons }\end{array}$ & $\begin{array}{l}\text { \# Up-regulated } \\
\text { DEGs }\end{array}$ & $\begin{array}{l}\text { \# Down-regulated } \\
\text { DEGs }\end{array}$ \\
\hline $0 \mathrm{~h}$ & 138 & 6 \\
$24 \mathrm{~h}$ & 72 & 82 \\
$48 \mathrm{~h}$ & 18 & 96 \\
1 week & 5 & 172 \\
4 weeks & 59 & 107 \\
\hline
\end{tabular}

two antioxidant enzymes, catalase and phenylalanine ammonialyase (Safari et al. 2013). Thus, there is ample physiological evidence underlying the impact of US to in vitro plant growth.

Our group has used in vitro plants of the model plant, potato (Solanum tuberosum L.), to advance our understanding of how US impacts plant growth in vitro. An initial biochemical study revealed that the activity of three antioxidant enzymes, glutathione reductase (GR), superoxide dismutase (SOD), and ascorbate peroxidase (APX), increased significantly after $24 \mathrm{~h}$ in response to US (20 min of $35 \mathrm{kHz}$, at $70 \mathrm{~W}$ ) (Dobránszki et al. 2017). Curiously, US-treated plantlets showed $20 \%$ longer shoots than control plantlets (not exposed to US) and 24\% higher shoot fresh weight (Dobránszki et al. 2017). In a bid to assess what changes might be occurring at the transcriptome level, additional studies were conducted. Using the same plant material, and assessing the response specifically to wounding in cut explants, Teixeira da Silva et al. (2019) detected the significant expression (up- or down-regulation) of 189 differentially expressed genes (DEGs) related to defense, stress response, and wound healing. The US itself up-regulated multiple stress-related DEGs within the first 2 days ( $0 \mathrm{~h}$ to $48 \mathrm{~h}$ ), but 4 -week-old plantlets survived and expressed a few stress-related DEGs (Dobránszki et al. 2019). In the latter study, US was delivered to stem explants through air (i.e., a dry environment) using an ultrasonicator. In this study, we were curious to determine if the same explants, when exposed to US through a liquid medium, via the use of piezoelectric ultrasound (PE-US), might display the same responses as to US via air.

\section{Materials and Methods}

\section{Plant Material and Growth Conditions}

All plant material and in vitro culture conditions were identical to those employed by Dobránszki et al. $(2017,2019)$ and Teixeira da Silva et al. (2019). In brief, single-node stem segments of "Desirée," including a single leaf, were excised from 4-weekold in vitro plantlets and plated for 4 weeks on Murashige and
Skoog (1962) medium free of plant growth regulators (PGRs). Plant material was sampled at five time points (at $0 \mathrm{~h}, 24 \mathrm{~h}, 48 \mathrm{~h}$, 1 week, and 4 weeks). Samples (explants at 0,24 , and $48 \mathrm{~h}$ and plantlets (leaves, stems, and roots) at 1 week and 4 weeks) were stored immediately at $-80{ }^{\circ} \mathrm{C}$ until further analysis.

\section{Ultrasonication of Explants}

Freshly cut explants were placed into $50-\mathrm{ml}$ glass beakers (90 explants/40-ml liquid MS/beaker; VWR International Kft., Debrecen, Hungary). A total of eight beakers were placed under sterile conditions into an ultrasonicator (Elmasonic X-tra $30 \mathrm{H}$; Elma Schmidbauer GmbH, Singen, Germany) and immersed into, and surrounded by, distilled water. Ultrasonication conditions were frequency $(35 \mathrm{kHz})$, temperature $\left(25^{\circ} \mathrm{C}\right)$, period (20 $\mathrm{min})$, and power $(70 \mathrm{~W})$. Ultrasonicated explants were placed directly onto solid PGR-free MS medium in glass jars (400 ml; OROSházaGLAS, Orosháza, Hungary) (30 explants/jar; 50-ml MS medium/jar). A total of 750 explants were prepared for each treatment.

\section{mRNA Isolation, Library Construction, and Sequencing}

Using methods described by Dobránszki et al. (2019) and Teixeira da Silva et al. (2019), total RNA was purified from the samples as three biological replicates. rRNA was removed from the 30 total RNA samples, and the three biological replicates were pooled. Ten mRNA libraries were derived from the three biological replicates of five treatments and five controls. Deep sequencing (150bp paired-end reads, expected data volume was $100 \mathrm{M}$ reads/sample) was conducted.

\section{Bioinformatic Evaluation and Functional Annotation of mRNA-Seq Datasets}

Dobránszki et al. (2019) and Teixeira da Silva et al. (2019) describe in more detail the bioinformatic processing, analysis of RNA-seq datasets, and functional annotation of significant DEGs. The software used to achieve this was SolTub 3.0 (https://plants.ensembl.org/Solanum_tuberosum/Info/Index) and FastQC v0.11.7 (https://github.com/s-andrews/FastQC) to quality check the FastQ files and to decide the trimming parameters. Other software used to achieve this was TrimGalore v0.5.0 (https://github.com/FelixKrueger/ TrimGalore); HISAT2 v2.1.0 (Kim et al. 2015); SeqMonk v1.42.0 program (https://github.com/s-andrews/SeqMonk); NCBI database using BlastX-fast in Blast2GO v5.2 (Götz et al. 2008); Gene3D, SFLD, SuperFamily, Coils, MobiDBLite, CDD, HAMAP, HMMPanther, HMMPfam, FprintScan, BlastProDom, ProfileScan, HMMTigr, and PatternScan; and KEGG maps (Kanehisa Laboratories; https://www.kegg.jp/kegg/kegg1.html; Kanehisa et al. 2017). 
Only DEGs with a $P$ value $\geq 0.05$ for the intensity difference filter in SeqMonk were exclusively considered for statistical analyses.

DEGs for heat shock proteins (HSPs) were verified on UniProt (https://www.uniprot.org/) and on the Spud DB Potato Genomics Resource (http://solanaceae.plantbiology. msu.edu/), which includes the InterPro domain matches function to confirm the correct identity of the HSP genes.

\section{RT-qPCR to Validate DEGs}

Using the protocols described in Dobránszki et al. (2019) and Teixeira da Silva et al. (2019), total RNA was isolated from 10 samples as three biological replicates. For the RT-qPCR analysis, we selected 10 DEGs from the RNA-seq datasets (PGSC0003DMG400024476, PGSC0003DMG400028182, PGSC0003DMG400046976, PGSC0003DMG400027202, PGSC0003DMG400045366, PGSC0003DMG400013740, PGSC0003DMG401030252, PGSC0003DMG400015318, PGSC0003DMG 400015287 , and PGSC0003D MG400010763) based on the most negative and positive changes in intensity in the SeqMonk logarithmic fold changes (LFC) values. We selected five commonly used reference genes (EF1 $\alpha$, elongation factor-1alpha; actin; tubulin; $G A P D H$, glyceraldehyde-3-phosphate dehydrogenase; sec3, exocyst complex component sec3) for RT-qPCR based on the Tang et al. (2017) results on validated reference genes in potato under abiotic stress. RT-qPCR primers (Suppl. Table 1) were used for the chosen DEGs and the five normalizing (reference) genes (GAPDH, actin, EF1 $\alpha$, sec3, tubulin). To compare the stability of expression intensity among the candidate reference genes, we used several statistical methods: geNorm (Vandesompele et al. 2002), NormFinder (Andersen et al. 2004), and BestKeeper (Pfaffl et al. 2004) based on the cycle quantification value $(\mathrm{Cq})$. The results were compared from the geNorm, NormFinder, and BestKeeper with the comprehensive ranking platform RefFinder (Xie et al. 2012) which was based on the geometric mean of the rankings of every single gene calculated by each statistical program. RTqPCR was performed and evaluated, and correlation coefficients (Spearman and Pearson) were calculated using Excel in Microsoft Office 2018 (Microsoft, Redmond, WA, USA).

\section{Protein Analysis by Two-Dimensional (2-D) Gel Electrophoresis}

Using the methodology reported earlier (Dobránszki et al. 2019; Teixeira da Silva et al. 2019), total protein was extracted from the five samples $(0 \mathrm{~h}, 24 \mathrm{~h}, 48 \mathrm{~h}, 1$ week, 4 weeks $)$ in three biological replicates from each sample and analyzed using the Agilent Protein 230 Kit (Agilent, Santa Clara, CA, USA) on an Agilent Bioanalyzer 2100 (Agilent) both under reducing (dithiothreitol) and nonreducing (distilled water) conditions.

\section{Morphological Parameters and Chlorophyll Content}

Several morphological parameters were assessed for control plantlets and plantlets exposed to PE-US at 4 weeks: shoot length $(\mathrm{mm})$, number of nodes/shoot, shoot and root fresh weight $(\mathrm{g} / \mathrm{vessel})$, and root length $(\mathrm{mm})$. In addition, chlorophyll (chl) $a, \operatorname{chl} b$, and total $\operatorname{chl}(a+b)$ content, and $\operatorname{chl} a / \operatorname{chl} b$ ratio were determined. Chl content was determined using the spectrophotometric method described in Dobránszki and Mendler-Drienyovszki (2014). Data were analyzed statistically by pairwise comparisons (independent samples $t$ test) using SPSS for Windows (SPSS $\AA$, version 25.0) at $P \leq 0.05$.

The analyses reported between "mRNA isolation, library construction, and sequencing" and "protein analysis by twodimensional (2-D) gel electrophoresis," except for the assessment of HSPs, are identical to those employed by Dobránszki et al. (2019) and Teixeira da Silva et al. (2019) and may include verbatim text.

\section{Results}

\section{RNA Expression Profiles: Global Changes}

We assessed the expression intensity of 40,430 genes. A total of $144,154,114,177$, and 166 sequences were either significantly up- or down-regulated at $0 \mathrm{~h}, 24 \mathrm{~h}, 48 \mathrm{~h}, 1$ week, and 4 weeks, respectively (Table 1; Fig. 1; Suppl. Fig. 1).

\section{Changes in Biological, Cellular, and Molecular Processes}

Biological, cellular, and molecular processes were significantly up- and down-regulated at $0 \mathrm{~h}, 24 \mathrm{~h}, 48 \mathrm{~h}, 1$ week, and 4 weeks (Suppl. Fig. 2). Among the most salient biological processes, response to stress was up-regulated at $0 \mathrm{~h}$ and down-regulated at $24 \mathrm{~h}, 48 \mathrm{~h}$, and 1 week. Other details of biological, cellular, and molecular processes are described in the Suppl. Results and Discussion.

Fig. 1 Total number of expressed genes in in vitro single-node stem potato explants in a comparison between the control (non-PE-US) and treatment (PE-US, piezoelectric ultrasound: $35 \mathrm{kHz} ; 70 \mathrm{~W}$; $20 \mathrm{~min})$ at $0 \mathrm{~h} \mathrm{(a),} 24 \mathrm{~h} \mathrm{(c),} 48 \mathrm{~h} \mathrm{(e);} 1$ week (g); and 4 weeks (i) and total number of significantly differentially expressed genes in

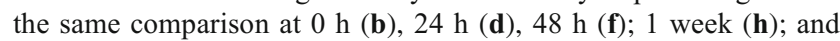
4 weeks (j). Scatter plots generated by SeqMonk 

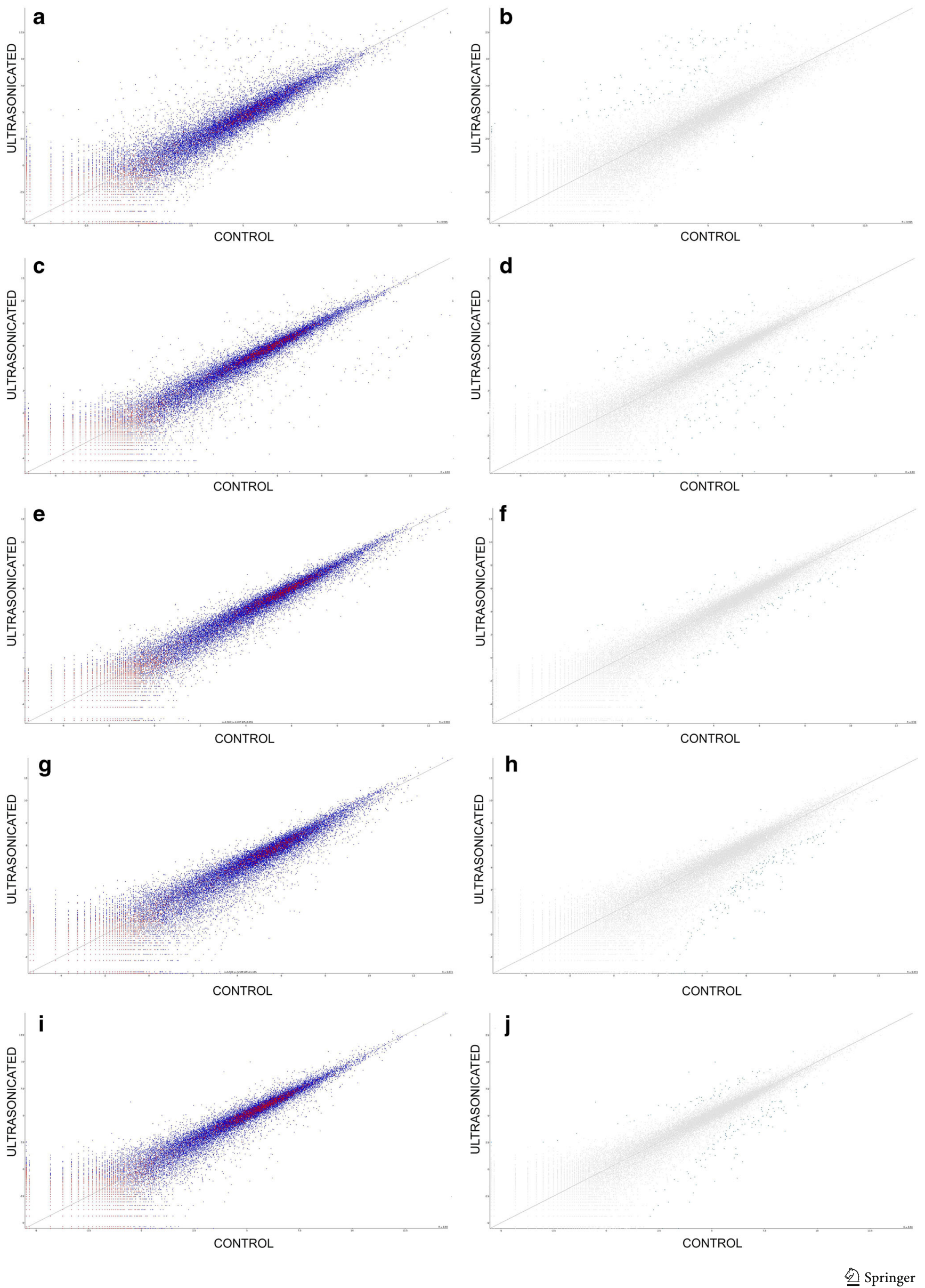


\section{Up- and Down-Regulated DEGs Related to Transcription Factors}

Using NCBI and NOG (non-supervised orthologous groups) descriptors, $21 \mathrm{TFs}$ were identified between $0 \mathrm{~h}$ and 4 weeks (Table 2). Twelve TFs were significantly up-regulated, while three were significantly down-regulated at $0 \mathrm{~h}$ and $24 \mathrm{~h}$ after the application of PE-US. Two Apetala2/ethylene responsive factor (AP2/ERF) TFs were significantly up-regulated at $0 \mathrm{~h}$ and one at 4 weeks. Two heat shock or heat stress TFs, as well as two GATA TFs, were significantly up-regulated after $0 \mathrm{~h}$ and $24 \mathrm{~h}$. One dehydration-responsive element-binding (DREB) TF was significantly up-regulated at $0 \mathrm{~h}$. One WRKY TF was up-regulated at $24 \mathrm{~h}$. Three other TFs (REVEILLE 1-like isoform X2; bHLH93-like; MYB48-like) were significantly up-regulated after $0 \mathrm{~h}$ and $24 \mathrm{~h}$. A MYB TF (protein REVEILLE 1-like isoform X2) was significantly upregulated at $0 \mathrm{~h}$, while another (protein RADIALIS-like 4) was significantly down-regulated at $0 \mathrm{~h}$.

\section{Stress-Related Enzymes}

Based on the NOG description of the DEGs that were significantly up- or down-regulated (Suppl. Table 2), immediately after PE-US (at $0 \mathrm{~h}$ ), several DEGs encoding stressrelated enzymes were up-regulated compared to the control, i.e., non-ultrasonicated samples. Up-regulation of
DEGs encoding annexin, universal stress protein, chitinase, methionine sulfoxide reductase, and catalase, as well as two DEGs encoding zinc finger proteins (ZFPs), six DEGs encoding glutathione $S$-transferase (GST), and 17 DEGs encoding HSPs, was detected. Five of those were variants of the StHsp70 gene (StHsp70-7, StHsp70-10, StHsp70-11, StHsp70-14, StHsp70-20; Table 3), which were specific to potato (Liu et al. 2018), and were primarily expressed at $0 \mathrm{~h}$. Among the 12 remaining DEGs that were identified as HSPs in NCBI, nine were confirmed as HSPs on the UniProt and Spud DB databases and were exclusively Hsp20, Hsp70, and Hsp90 proteins (Table 3). Down-regulation of chitinase and GST occurred by $24 \mathrm{~h}$ and $48 \mathrm{~h}$ in ultrasonicated plant material, but up-regulation of the universal stress protein was still detected in ultrasonicated plantlets at $24 \mathrm{~h}$, but it was only downregulated in 1-week-old ultrasonicated plantlets, similar to ZFPs. Up-regulation of a DEG linked to plant lipoxygenase in the PE-US sample was detected at $24 \mathrm{~h}$, but two DEGs were down-regulated at $48 \mathrm{~h}$ after ultrasonication.

\section{Up- and Down-Regulation of DEGs Related to Metabolic Processes}

When assessing metabolic processes between $0 \mathrm{~h}$ and $4 \mathrm{w}$, the expression of DEGs was observed in 10 metabolic processes
Table 2 Significantly up- and down-regulated transcription factors in response to piezoelectric ultrasound $(35 \mathrm{kHz}$; $70 \mathrm{~W} ; 20 \mathrm{~min}$ )

\begin{tabular}{|c|c|c|c|c|c|}
\hline Description $^{1}$ & $0 \mathrm{~h}$ & $24 \mathrm{~h}$ & $48 \mathrm{~h}$ & 1 week & 4 weeks \\
\hline $\begin{array}{l}\text { AP2-like ethylene-responsive transcription factor TOE3 } \\
\text { isoform X1 }\end{array}$ & -3.80 & & & & \\
\hline $\mathrm{AP} 2 / \mathrm{ERF}$ and $\mathrm{B} 3$ domain-containing transcription factor RAV1 & & & & & -1.67 \\
\hline Basic leucine zipper 43 & & & & 3.39 & \\
\hline Basic leucine zipper 61-like & & & & & 4.93 \\
\hline Dehydration-responsive element-binding protein 2D-like & -4.47 & & & & \\
\hline Ethylene-responsive transcription factor ABR1-like isoform X1 & -4.50 & & & & \\
\hline Ethylene-responsive transcription factor ERF010-like & & & & 2.59 & \\
\hline GATA transcription factor-like protein & -6.90 & & & & \\
\hline GATA transcription factor 4-like & & -1.77 & & & \\
\hline Heat shock factor protein HSF30 & -6.74 & & & & \\
\hline Heat stress transcription factor A-7a-like isoform X2 & & -2.66 & & & \\
\hline MYB family transcription factor EFM-like & & & & & 2.34 \\
\hline Probable WRKY transcription factor 51 & & 3.79 & & & \\
\hline Probable WRKY transcription factor 72 & & -4.97 & & & \\
\hline Probable WRKY transcription factor 75 & & & & & 2.66 \\
\hline Protein RADIALIS-like $4^{2}$ & 4.09 & & & & \\
\hline Protein REVEILLE 1-like isoform $X 2^{3}$ & -3.38 & & & & \\
\hline Transcription factor bHLH93-like & -4.16 & -2.81 & & & \\
\hline Transcription factor MYB48-like & & -3.66 & & & 2.12 \\
\hline Two-component response regulator ARR15 & 4.89 & & & & \\
\hline Zinc finger protein CONSTANS-LIKE 16-like & & & 2.34 & & \\
\hline
\end{tabular}

Negative values indicate up-regulation; positive values indicate down-regulation

${ }^{1}$ Descriptions based on NCBI or NOG

${ }^{2}$ A MYB-related factor (https://www.uniprot.org/uniprot/Q1G3C4)

${ }^{3}$ A MYB TF (https://www.uniprot.org/uniprot/F4KGY6) (Rawat et al. 2009) 
Table 3 DEGs of 17 heat shock proteins (HSPs) whose expression changed in response to piezoelectric ultrasound (PE-US) treatment

\begin{tabular}{|c|c|c|c|}
\hline \multirow[b]{2}{*}{ NCBI ID No.* } & \multirow[b]{2}{*}{ Expression level after PE-US ${ }^{1}$} & \multicolumn{2}{|c|}{ Description according to } \\
\hline & & $\begin{array}{l}\text { Liu et al. (2018) } \\
\text { Gene name }\end{array}$ & $\begin{array}{l}\text { UniProt/Spud DB** } \\
\text { Protein name }\end{array}$ \\
\hline PGSC0003DMG400024707 & $-6.13^{2}$ & StHsp $70-20$ & Hsp70 \\
\hline PGSC0003DMG400001442 & -5.57 & & Chaperonin $\operatorname{clpA} / \mathrm{B}$ \\
\hline PGSC0003DMG402003209 & -5.86 & & RNA binding \\
\hline PGSC0003DMG400003219 & -6.95 & & Hsp20 \\
\hline PGSC0003DMG400009509 & -4.90 & & Hsp90 \\
\hline PGSC0003DMG400024644 & -6.52 & & Chaperonin $\operatorname{clpA} / \mathrm{B}$ \\
\hline PGSC0003DMG400014212 & $-8.58^{2}$ & StHsp 70-10 & Hsp70 \\
\hline PGSC0003DMG400009173 & -8.15 & & Hsp20 \\
\hline PGSC0003DMG400023622 & -4.56 & & Hsp20 \\
\hline PGSC0003DMG401028907 & $-7.96^{2}$ & StHsp70-11 & $\mathrm{Hsp} 70^{4}$ \\
\hline PGSC0003DMG400030426 & -6.29 & & Hsp20 \\
\hline PGSC0003DMG400030427 & -7.33 & & Hsp20 \\
\hline PGSC0003DMG400030089 & $-7.95^{2} /-1.71^{3}$ & StHsp 70-14 & Hsp70 \\
\hline PGSC0003DMG400027611 & -7.67 & & Hsp70 \\
\hline PGSC0003DMG400009255 & -9.18 & & Hsp20 \\
\hline PGSC0003DMG400000444 & $-6.06^{2}$ & StHsp 70-7 & Hsp70 \\
\hline PGSC0003DMG400028634 & -7.96 & & Hsp70 \\
\hline
\end{tabular}

${ }^{1}$ Negative values indicate up-regulation; positive values indicate down-regulation

${ }^{2}$ At $0 \mathrm{~h}$

${ }^{3}$ At $48 \mathrm{~h}$

${ }^{4}$ According to UniProt/Spud DB, this was classified as Hsp90 (Heat shock protein 83)

*The precise HSP number was not indicated in the NOG database

**UniProt (https://www.uniprot.org/) and on the Spud DB Potato Genomics Resource (http://solanaceae. plantbiology.msu.edu/) related to amino acids; seven related to carbohydrates; 10 related to lipids, fatty acids, and membrane structures; two each related to nucleotides and vitamins; and 15 related to basic processes (Suppl. Tables 2 and 3).

\section{Validity of DEG Analysis by RT-qPCR}

The RefFinder ranking results of the candidate reference genes are shown in Supplementary Table 3. Under US treatment, the ranking order (from the most stable to the least stable) was GAPDH $>$ EF1 $\alpha>$ tubulin $>\sec 3>$ actin. Based on the RefFinder ranking results, we selected the GAPDH gene as reference gene for the DEG validation. RT-qPCR, which served as the method of choice to validate RNA-seq data, indicated that all of the chosen DEGs were truly positively up- or down-regulated DEGs (Suppl. Fig. 3; Suppl. Table 4). Between SeqMonk LFC and RT-qPCR LFC, the correlation coefficients were 0.86 and 0.90 (Spearman and Pearson correlations, respectively; Suppl. Fig. 3), i.e., SeqMonk LFC and RT-qPCR LFC were strongly and positively correlated.

\section{Total Protein Analysis}

Protein production in the five samples differed, indicated by differences between control and treated samples, as revealed by total protein 2-D gel electrophoresis (Suppl. Fig. 4; Suppl. Table 5).

\section{Morphological Parameters and Chlorophyll Content}

Compared with untreated control plantlets, plantlets exposed to PE-US showed significantly shorter shoots but significantly longer roots, and shoot and root fresh weight were significantly higher. Moreover, chl $b$ and total chl were significantly lower, but the chl $a / b$ ratio was significantly higher in plantlets exposed to PE-US (Table 4).

\section{Discussion}

This study aimed to assess, using a KEGG-based transcriptomic analysis, the changes taking place in freshly 
Table 4 Morphological parameters and chlorophyll (chl) content ( $\mu \mathrm{g} / 1$ $\mathrm{g}$ fresh weight $\mathrm{FW}$ ) of in vitro potato plantlets 4 weeks after piezoelectric ultrasound (PE-US) treatment

\begin{tabular}{|c|c|c|c|}
\hline PE-US treatment & 0 min (control) & PE-US & Sig. \\
\hline \multicolumn{4}{|c|}{ Morphological parameters } \\
\hline SL (mm) & $74.11 \pm 1.53$ & $59.15 \pm 1.77$ & $*$ \\
\hline $\mathrm{NN}$ & $6.91 \pm 0.09$ & $6.84 \pm 0.14$ & \\
\hline SFW (g/vessel) & $3.96 \pm 0.27$ & $5.09 \pm 0.16$ & $*$ \\
\hline $\mathrm{RL}(\mathrm{mm})$ & $48.97 \pm 1.29$ & $58.38 \pm 2.12$ & $*$ \\
\hline RFW (g/vessel) & $2.84 \pm 0.28$ & $4.79 \pm 0.23$ & $*$ \\
\hline \multicolumn{4}{|c|}{ Chlorophyll content } \\
\hline $\operatorname{chl} a$ & $840.1 \pm 68.8$ & $677.7 \pm 31.7$ & \\
\hline $\operatorname{chl} b$ & $232.9 \pm 18.3$ & $155.7 \pm 7.9$ & $*$ \\
\hline $\operatorname{chl} a+\operatorname{chl} b$ & $1074.9 \pm 87.1$ & $834.9 \pm 39.6$ & $*$ \\
\hline $\operatorname{chl} a / \operatorname{chl} b$ & $3.60 \pm 0.05$ & $4.36 \pm 0.04$ & $*$ \\
\hline
\end{tabular}

*Significant differences $(P \leq 0.05)$ in each row between control, i.e., nonultrasonicated and ultrasonicated (PE-US) samples according to the Student's $t$ test. Values indicate means $\pm \mathrm{SD}$

$S L$ shoot length, $R L$ root length, $N N$ number of nodes/shoot, $S F W$ shoot fresh weight, $R F W$ root fresh weight, chl $a$ chlorophyll a, chl $b$ chlorophyll $b, P E-U S$ piezoelectric ultrasound treatment

prepared stem internode explants that were exposed to a stress and PE-US and then left to grow for 4 weeks until in vitro plantlets had developed. In addition, some morphological parameters were assessed in 4-week-old plantlets. The primary focus was placed on stress-related enzymes, HSPs and TFs.

\section{Metabolic Processes, Morphological Parameters, and Chlorophyll Content}

A more detailed discussion and description of the possible links between the stress response and amino acids (Fig. 2), carbohydrates (Fig. 3), lipids and fatty acids (Fig. 4), nucleotides (Fig. 5), vitamins (Fig. 6), and other biological processes (Figs. 7 and 8) can be found in the Suppl. Results and Discussion. However, there are some obvious differences compared with our earlier study on ultrasonication, when the US was propagated by air (Dobránszki et al. 2019), which are highlighted here. In present study, 10 pathways related to the amino acid metabolism (Fig. 2) were affected, while in our earlier study, when ultrasonic stress was transmitted by air (Dobránszki et al. 2019), the expression intensities of DEGs of enzymes related to only 7 amino acid metabolism pathways changed. Unlike ultrasonication propagated by air (Dobránszki et al. 2019), the PE-US caused the upregulation of a DEG for aspartate transaminase resulting changes in the metabolism of the arginine and proline metabolism, as well as arginine biosynthesis and phenylalanine, tyrosine, and tryptophan biosynthesis $24 \mathrm{~h}$ after the ultrasonication. Up-regulation of those pathways results in increased production of glyoxalate or pyruvate, glutamate and phenylpyruvate, phenylalanine, 4-hydroxyphenylpyruvate, and tyrosine. By changing the level of their precursors, like 4hydroxyphenylpyruvate, which can be converted to homogentisate, the level of tocopherols, a well-known antioxidant in living organism, may also change. Beside the upregulation of the tryptophan biosynthesis, the production of Ltryptophanyl-tRNA was down-regulated $24 \mathrm{~h}$ and 4 weeks after PE-US (Fig. 5), causing potentially an increase in the level of available L-tryptophan. Changes in the level of tryptophan affect the level of auxins, glucosinolates, and phytoalexins, since it is their precursor. A significant increase of the fresh weights of shoots and roots and significantly longer roots of 4-week-old plantlets after PE-US (Table 4) can be linked to the affected auxin level. Moreover, the level of tryptophan is connected to the level of serotonin and melatonin (Kaur et al. 2015) as both are stressrelated compounds. Increased production of glutamate can serve as a substrate for the production of $\gamma$-aminobutyrate (GABA). GABA is a signaling molecule in the stress adaptation (Hildebrandt et al. 2015).

Moreover, the up-regulation of a DEG related to the aminocyclopropane-1-carboxylate oxidase immediately $(0 \mathrm{~h})$ after the ultrasonication (PE-US) leads to increased production of ethylene (cysteine and methionine metabolism, Fig. 2). Up-regulation of the diterpenoid biosynthesis (Fig. 4) leads to increased production of gibberellic acid metabolites $24 \mathrm{~h}$ after ultrasonication by PE-US, but it was not occurred when US was transmitted by air (Dobránszki et al. 2019). By the end of the 4-week subculture, the shoot length of 4-week-old potato plantlets decreased significantly in ultrasonicated plantlets (Table 4). This aftereffect may be connected to the upregulation of a DEG for gibberellin $2 \beta$-dioxygenase resulting in the increase of GA metabolites. Similarly, down-regulation of phosphoethanolamine N-methyltransferase (PEAMT) at $24 \mathrm{~h}$ and 1 week may be linked to the shorter shoots after PE-US.

By up-regulating GST immediately $(0 \mathrm{~h})$ after PE-US caused change in glutathione metabolism (Fig. 8) and thereby in the redox state of the plants, while this was not detected after US treatment when US was propagated by air. Similarly, changes in the sulfur metabolism (Fig. 7) were detected only after PE-US.

Porphyrin and chlorophyll metabolism (Fig. 8) were upregulated $24 \mathrm{~h}$ after PE-US resulting in the possible degradation of chlorophyll a and $\mathrm{b}$, while the expression intensity of the DEG responsible for chlorophyllase was not affected when ultrasound was propagated by air. Accordingly, the chl $a+\operatorname{chl} b$ and the chl $b$ contents of the ultrasonicated plantlets by PE-US were significantly lower compared with the control plantlets at the end of the subculture (Table 4).

Even if the exact and targeted comparison of the effects of ultrasonication propagated by air (Dobránszki et al. 2019) or liquid (present study) deserves and needs further and a more detailed analysis to reveal how 
UP

DOWN

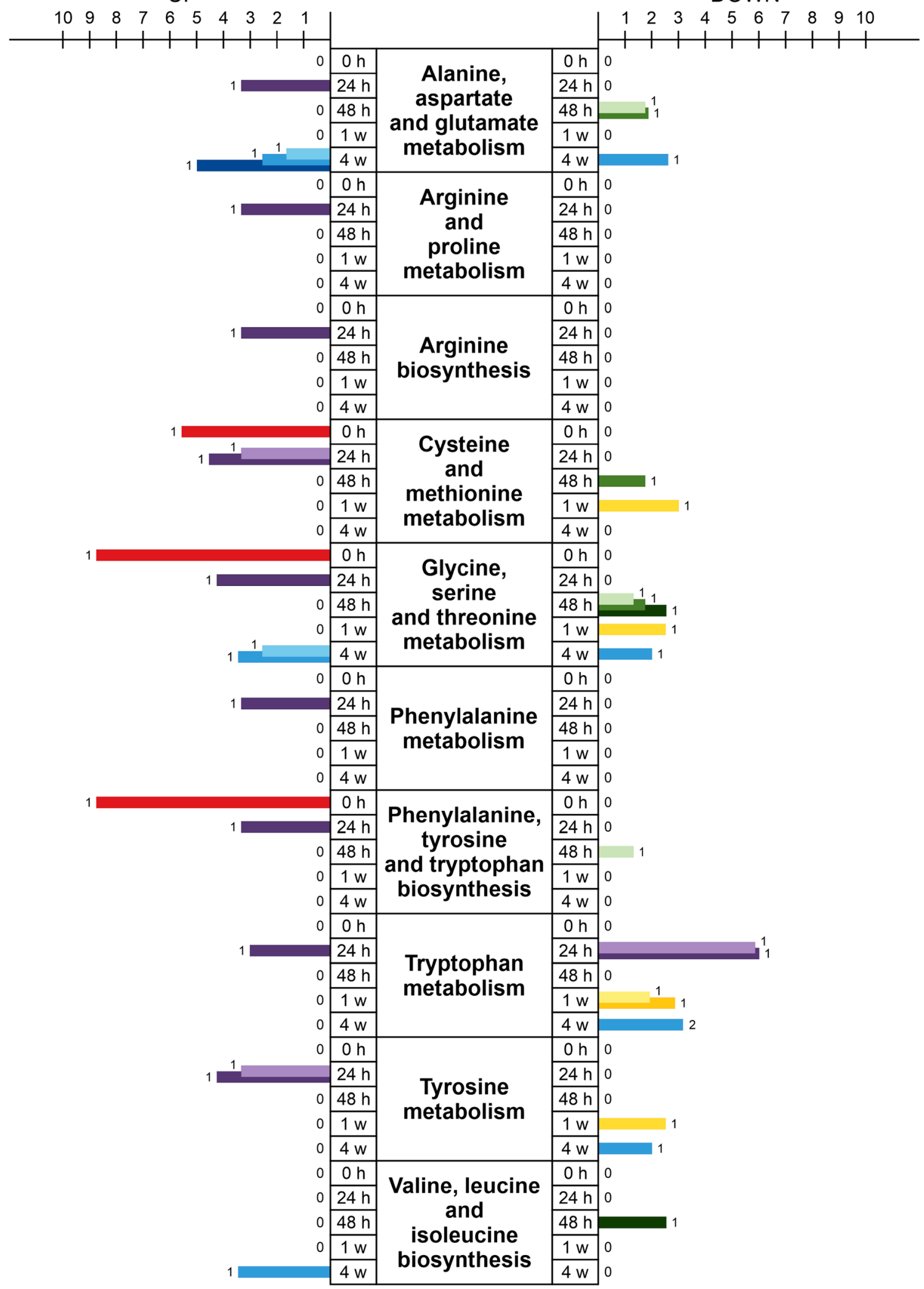

Fig. 2 Description of number of up- and down-regulated differentially expressed genes (DEGs), and their intensity, of processes associated with amino acids in plant material originating from in vitro single-node stem potato explants at $0 \mathrm{~h}, 24 \mathrm{~h}, 48 \mathrm{~h}, 1$ week, and 4 weeks after treatment of single-node explants with piezoelectric ultrasound $(35 \mathrm{kHz} ; 70 \mathrm{~W}$;
$20 \mathrm{~min}$ ). In columns where the number of DEGs representing the same enzyme exceeds 1 , the highest expression intensity is displayed. In columns where there are overlapping columns, these represent DEGs of different enzymes at the same time point 
Fig. 3 Description of number of up- and down-regulated differentially expressed genes (DEGs), and their intensity, of processes associated with carbohydrates in plant material originating from in vitro singlenode stem potato explants at $0 \mathrm{~h}$, $24 \mathrm{~h}, 48 \mathrm{~h}, 1$ week, and 4 weeks after treatment of single-node explants with piezoelectric ultrasound $(35 \mathrm{kHz} ; 70 \mathrm{~W}$; $20 \mathrm{~min}$ ). In columns where the number of DEGs representing the same enzyme exceeds 1 , the highest expression intensity is displayed. In columns where there are overlapping columns, these represent DEGs of different enzymes at the same time point

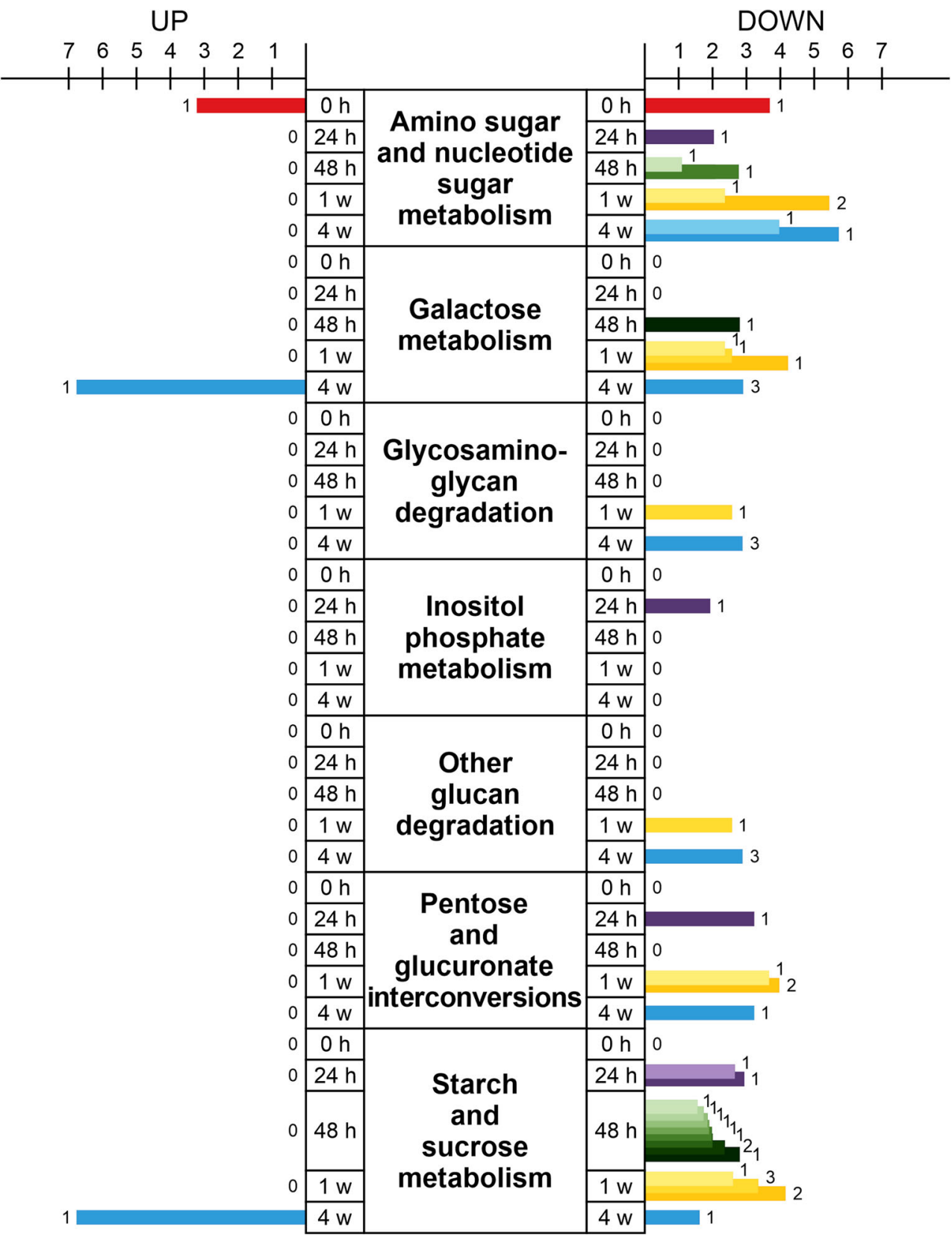

differently they changed the metabolism of the plants, the differences describe above indicate that they cause various levels of the abiotic stress to the plants.

\section{Stress-Related Enzymes}

Up-regulation of DEGs linked to stress enzymes in ultrasonicated samples at $0 \mathrm{~h}$ serves as an indicator of the stress caused by US. Significantly regulated DEGs for annexins, ZFPs, chitinases, and several stress-related enzymes such as methionine sulfoxide reductase and GST, which scavenge reactive oxygen species (ROS), were detected. The primary role of GST in scavenging ROS was already reported in an earlier paper related to activation of the antioxidant system of in vitro potato plantlets after ultrasonication (Dobránszki et al. 2017). Thus, upregulation of six DEGs encoding GST confirms our earlier finding, similar to the up-regulation of other ROSscavenging enzymes, like catalase.

\section{Heat Shock Proteins and Heat Shock Factors}

HSPs participate in response to various abiotic stresses, such as low or high temperature, water deficit, flooding, salinity, heavy metal stress, high light intensity, or even wounding (Mishra et al. 2018). HSPs act as chaperones, maintain the 
Fig. 4 Description of number of up- and down-regulated differentially expressed genes (DEGs), and their intensity, of processes associated with lipids in plant material originating from in vitro single-node stem potato explants at $0 \mathrm{~h}, 24 \mathrm{~h}, 48 \mathrm{~h}, 1$ week, and 4 weeks after treatment of single-node explants with piezoelectric ultrasound $(35 \mathrm{kHz}$; $70 \mathrm{~W} ; 20 \mathrm{~min}$ ). In columns where the number of DEGs representing the same enzyme exceeds 1 , the highest expression intensity is displayed. In columns where there are overlapping columns, these represent DEGs of different enzymes at the same time point
UP
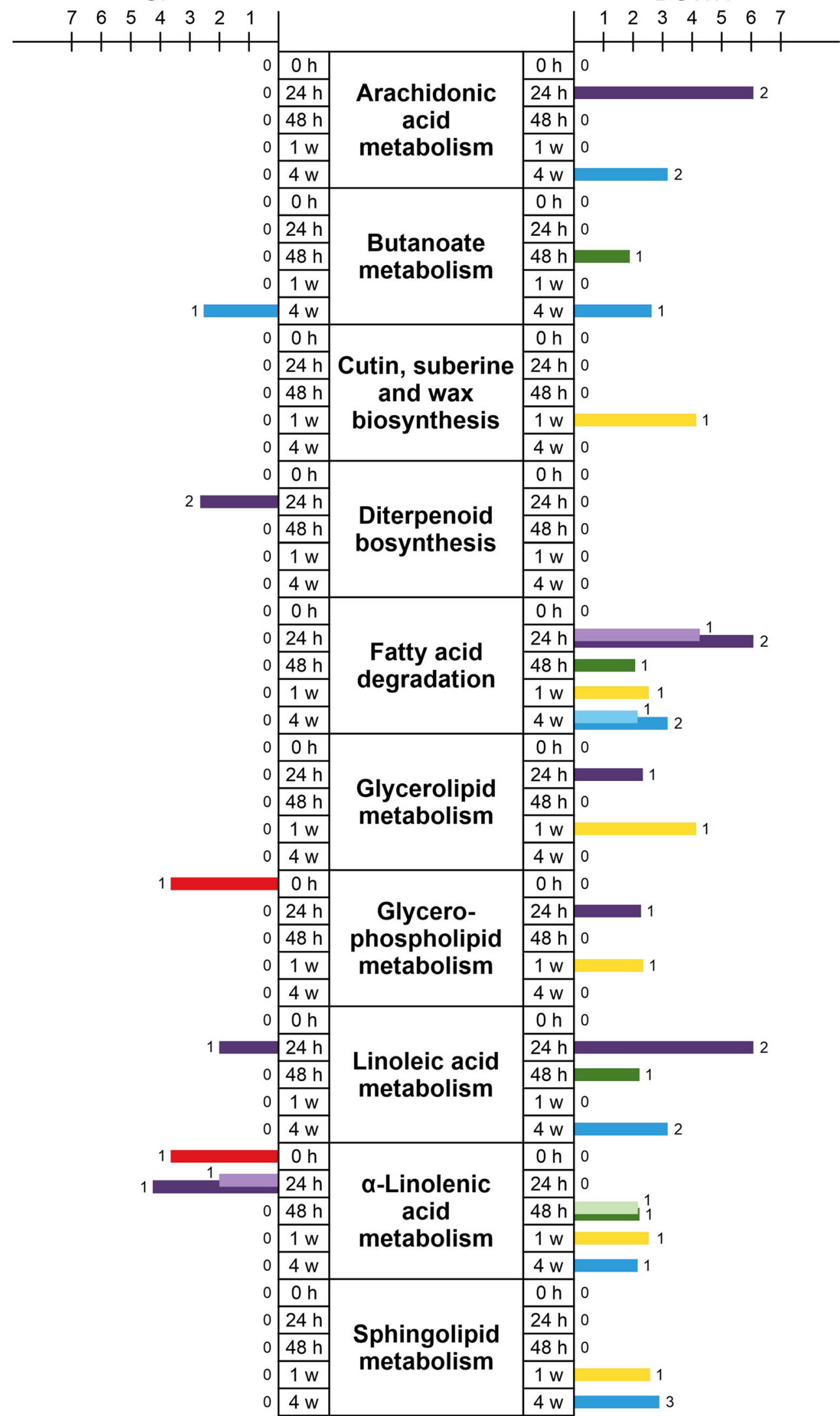
UP

DOWN

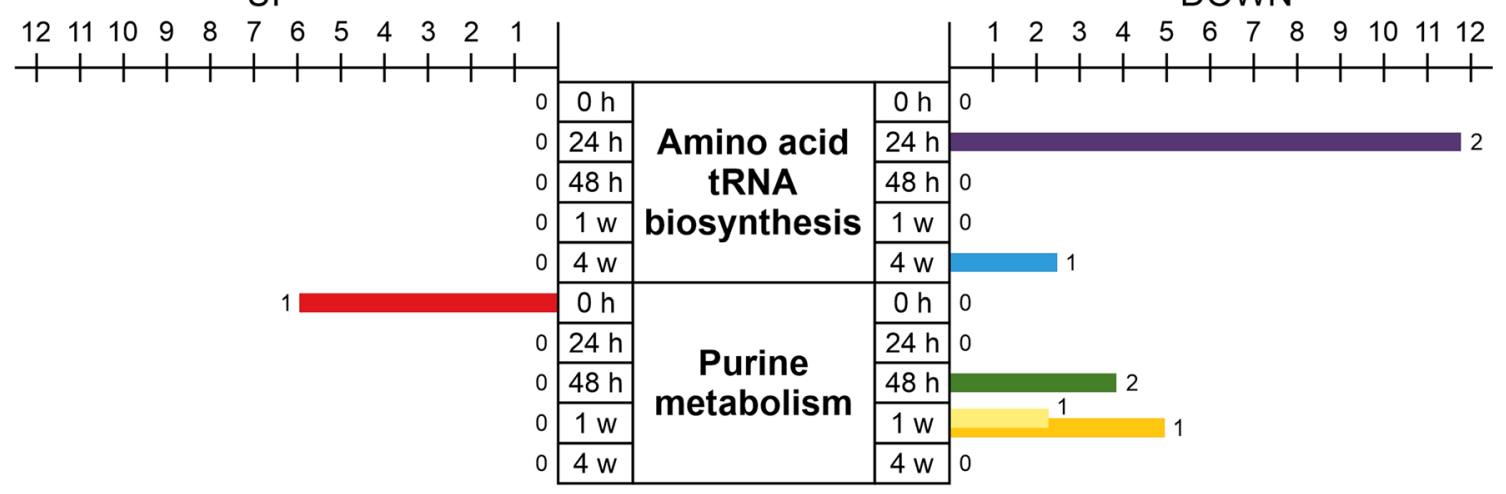

Fig. 5 Description of number of up- and down-regulated differentially expressed genes (DEGs), and their intensity, of processes associated with nucleotides in plant material originating from in vitro single-node stem potato explants at $0 \mathrm{~h}, 24 \mathrm{~h}, 48 \mathrm{~h}, 1$ week, and 4 weeks after treatment of single-node explants with piezoelectric ultrasound $(35 \mathrm{kHz} ; 70 \mathrm{~W}$;
$20 \mathrm{~min}$ ). In columns where the number of DEGs representing the same enzyme exceeds 1, the highest expression intensity is displayed. In columns where there are overlapping columns, these represent DEGs of different enzymes at the same time point homeostasis and redox status of cells, maintain protein structures, and participate in calmodulin-mediated signaling, while ROS production can trigger HSP production and their de novo synthesis (Mishra et al. 2018). The up-regulation of 17 HSP DEGs immediately (at $0 \mathrm{~h}$ ) after PE-US, including five proved earlier to be specific to potato (Liu et al. 2018), is not surprising considering their known roles and functions in abiotic and oxidative stress. The three HSPs found in this study in response to PE-US, Hsp20, Hsp70, and Hsp90, are involved in several functions related to abiotic stress (Wang et al. 2004). However, their up-regulation was not reported yet in response to sound or US in plants. In our earlier study (Dobránszki et al. 2019) in which in vitro nodal explants of potato were ultrasonicated using the same strength of US $(35 \mathrm{kHz}, 70 \mathrm{~W})$ and irradiation period $(20 \mathrm{~min})$ with an ultrasonicator in which the attenuation of US waves occurred in air, no DEGs coding for HSPs were up-regulated.

In A. thaliana, heat shock factors (HSFs) bind to the promotor region of an AP2/ERF, DREB (Sazegari et al. 2015). Abiotic stress can activate heat stress TFs, or HSFs, which regulate the expression of HSPs, which are coded by heat stress-responsive genes (Guo et al. 2016). Despite its name and apparent exclusive link to heat stress, HSPs are also activated by other abiotic stresses, such as drought and osmotic or salt stress (Guo et al. 2016). Our paper may represent the first discovery of the up-regulated expression of HSPs in response to US stress. ERFs are regulators of, and are often upregulated by, abiotic stresses and ROS, including binding to drought-responsive elements, and the activation of ERFs activates HSF and HSP genes, conferring heat tolerance (Müller
Fig. 6 Description of number of up- and down-regulated differentially expressed genes (DEGs), and their intensity, of processes associated with vitamins in plant material originating from in vitro singlenode stem potato explants at $0 \mathrm{~h}$, 24 h, 48 h, 1 week, and 4 weeks after treatment of single-node explants with piezoelectric ultrasound $(35 \mathrm{kHz} ; 70 \mathrm{~W}$; $20 \mathrm{~min}$ ). In columns where the number of DEGs representing the same enzyme exceeds 1 , the highest expression intensity is displayed. In columns where there are overlapping columns, these represent DEGs of different enzymes at the same time point

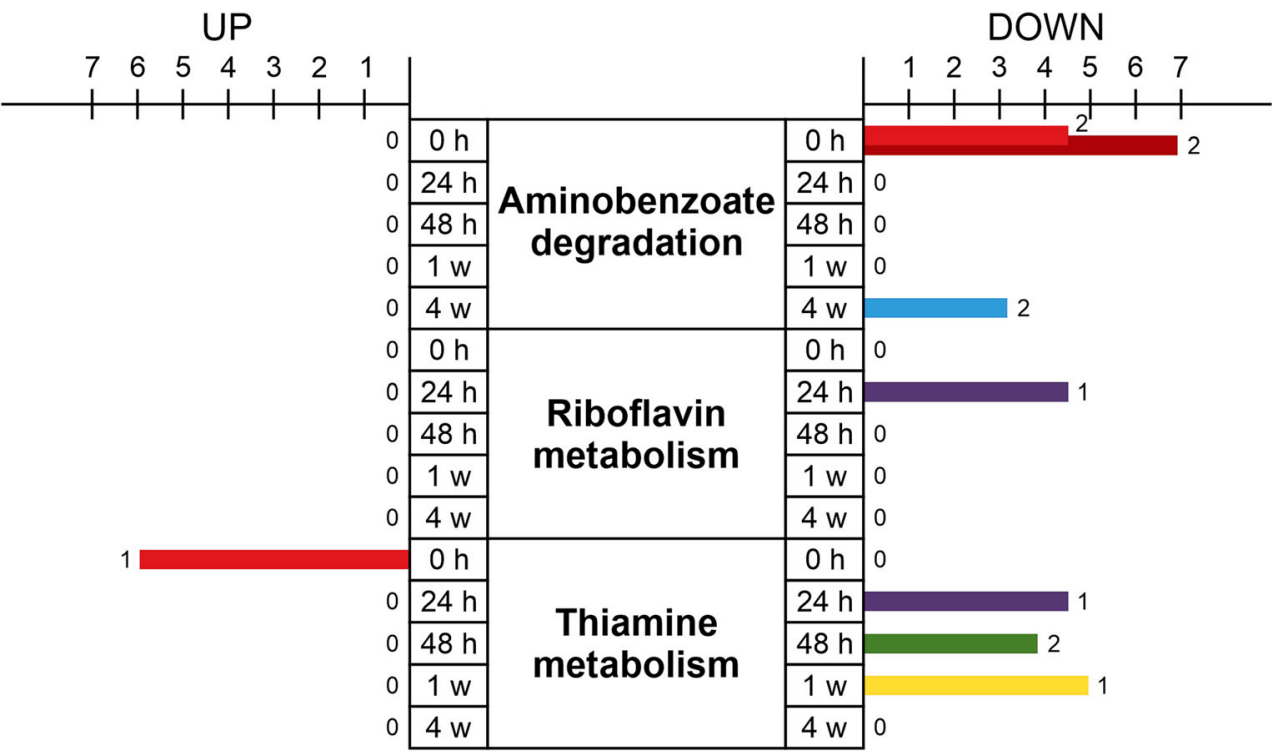


Fig. 7 Description of number of up- and down-regulated differentially expressed genes (DEGs), and their intensity, of processes associated with basic processes (group I) in plant material originating from in vitro single-node stem potato explants at $0 \mathrm{~h}, 24 \mathrm{~h}, 48 \mathrm{~h}, 1$ week, and 4 weeks after treatment of singlenode explants with piezoelectric ultrasound $(35 \mathrm{kHz} ; 70 \mathrm{~W}$;

$20 \mathrm{~min}$ ). In columns where the number of DEGs representing the same enzyme exceeds 1 , the highest expression intensity is displayed. In columns where there are overlapping columns, these represent DEGs of different enzymes at the same time point
UP

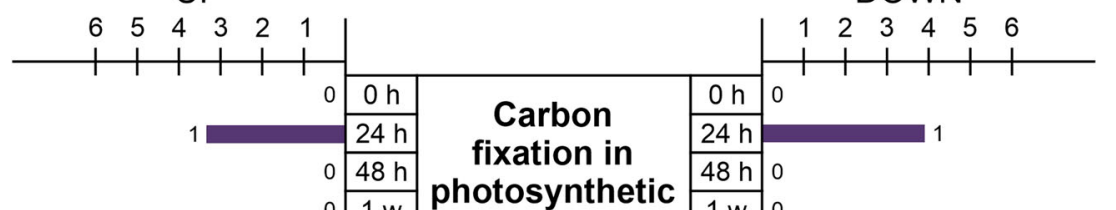

DOWN

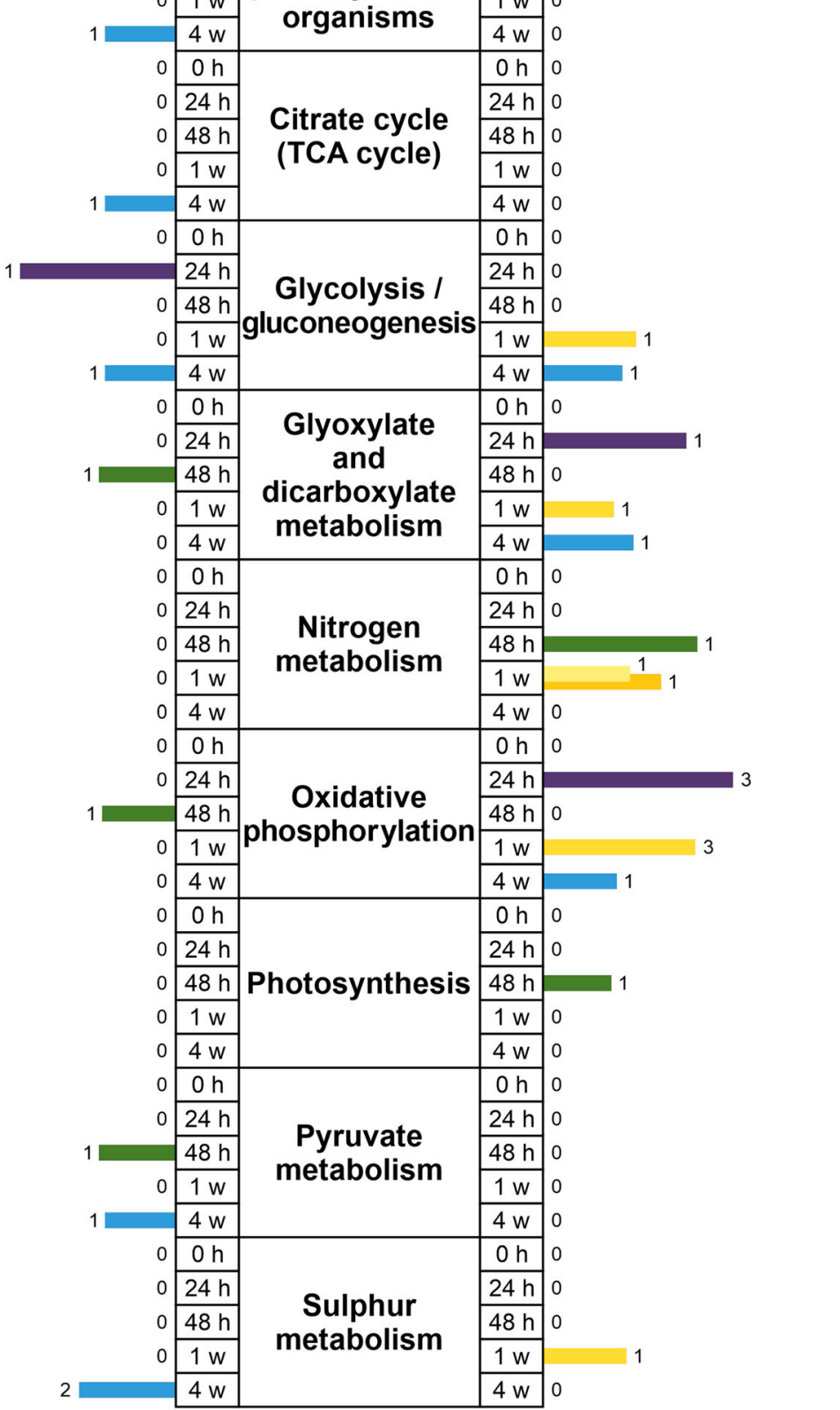

and Munné-Bosch 2015). The up-regulation of ERF TFs might be in response to an increased ethylene level in in vitro plants in response to wounding caused by US (Savatin et al. 2014).

\section{Transcription Factors}

In this study, in response to PE-US, the expression of 12 TFs was significantly up-regulated in potato stem explants at $0 \mathrm{~h}$ or
$24 \mathrm{~h}$ after the stress was applied (Table 2). An earlier study on potato that examined the impact of explant preparation and cutting noted that eight TFs (ethylene-responsive TF ABR1like isoform X1, ERF020-like, ERF027-like, ERF061, ERF109-like, probable WRKY TF 40 and 53, and TF bHLH35) were significantly up-regulated in response to cutting-induced wounding during explant preparation although they were then down-regulated $24 \mathrm{~h}$ later (Teixeira da Silva et al. 2019). A separate study in potato discovered 
UP

DOWN

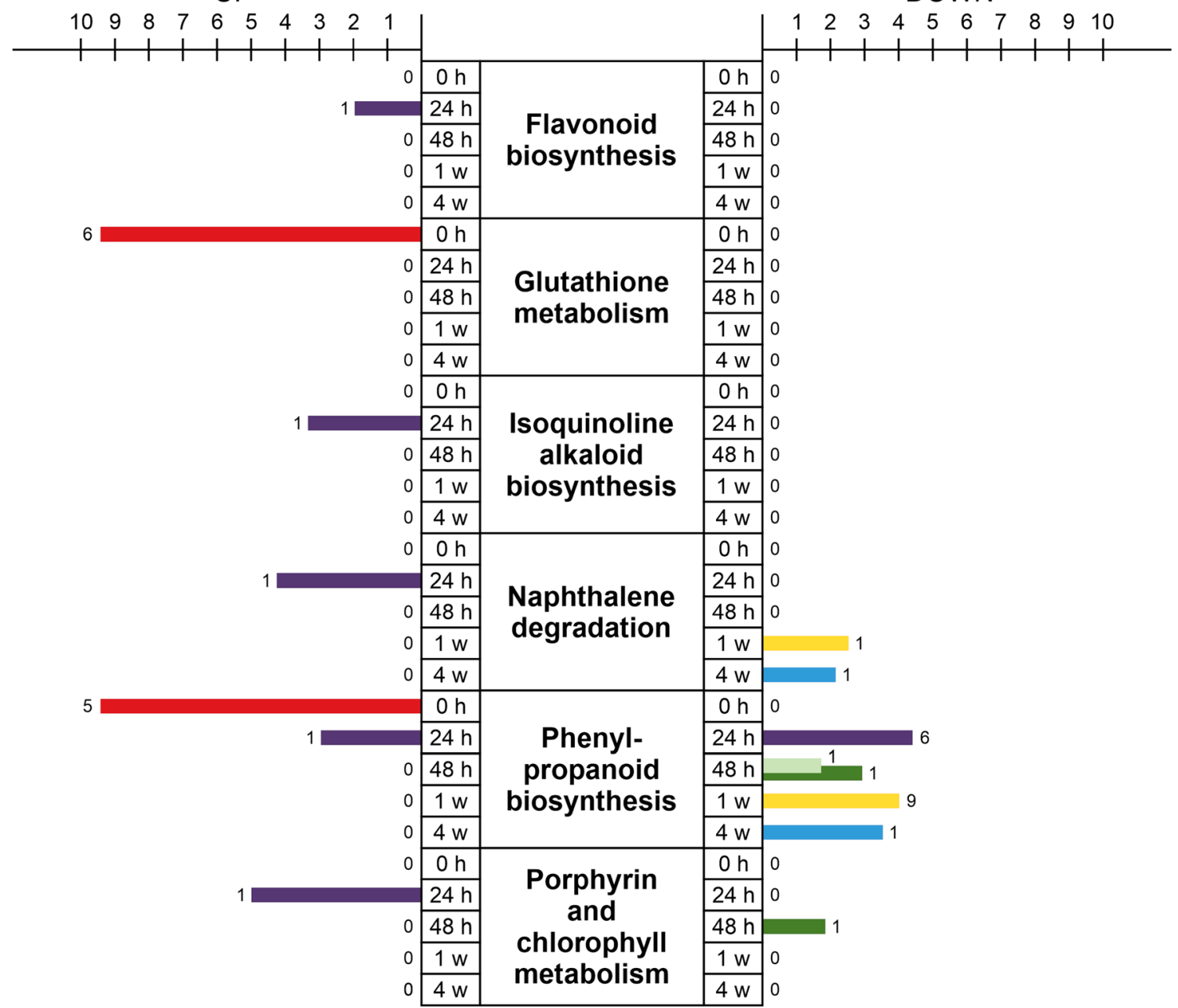

Fig. 8 Description of number of up- and down-regulated differentially expressed genes (DEGs), and their intensity, of processes associated with basic processes (group II) in plant material originating from in vitro single-node stem potato explants at $0 \mathrm{~h}, 24 \mathrm{~h}, 48 \mathrm{~h}, 1$ week, and 4 weeks after treatment of single-node explants with piezoelectric

the up- or down-regulation of nine TFs, including ERFs and four probable WRKY TFs, in response to US, with one heat stress TF (C-1), which was significantly down-regulated immediately after US application (Dobránszki et al. 2019). When Ghosh et al. (2016) stimulated A. thaliana with 0.5$3 \mathrm{kHz}$ of sound vibration, $13 \mathrm{TFs}$ were up-regulated, including ERF, DREB, WRKY, and MYB TFs.

\section{Conclusion}

Previously, a transcriptomic profile was created for potato stem explants exposed to an air-based US delivery system (Dobránszki et al. 2019). This study aimed to understand the transcriptomic changes in a single-node stem potato explant over 4 weeks in response to liquid-based PE-US. The DEGs of numerous stress-related elements, such as HSPs, TFs, or ultrasound ( $35 \mathrm{kHz} ; 70 \mathrm{~W} ; 20 \mathrm{~min})$. In columns where the number of DEGs representing the same enzyme exceeds 1 , the highest expression intensity is displayed. In columns where there are overlapping columns, these represent DEGs of different enzymes at the same time point

antioxidant enzymes, were up-regulated in response to PEUS, especially immediately after the stressor was applied. Of note was the first discovery of HSPs in US-stressed plants, in particular Hsp20, Hsp70, and Hsp90 proteins. While shoot length was reduced by about $20 \%$ in 4 -week-old in vitro potato plantlets that had been exposed to PE-US, with a concomitant decrease in chl-related parameters, namely, a $23 \%$ decrease in total chl content and $33 \%$ in chl $b$ content, shoot weight and root-related parameters (root length and weight) were improved by $30 \%, 23 \%$, and $68 \%$, respectively. Transcriptomic analysis and annotation of DEGs to enzyme functions of PE-US-treated plant material at five different phases of in vitro growth within a single subculture period of 4 weeks confirmed that treated plantlets showed modified metabolism. Some modifications in metabolism revealed on transcriptomic analysis are in link with morphological parameters and chl content of the 4-week-old plantlets. Studying 
changes in the expression profile over this time period made it possible to detect DEGs related to abiotic stress, mainly immediately $(0 \mathrm{~h}$ and $24 \mathrm{~h})$ after exposing the explants to ultrasonication. It was also possible to detect DEGs related to changes in metabolism of plantlets, and those changes can lead to modified growth and development. Thus, even though PE-US constitutes an acute abiotic stress, potato plants displayed a metabolic system that showed robust stress defense, accompanied by modifications in growth-related processes, but ultimately growth recovery within 4 weeks.

Authors' Contributions The experiments were conceived by JD. JD, NH, and JATdS designed the experiments. In vitro cultures were established by JD. NH and AG conducted bioinformatics analyses. BT conducted the RT-qPCR analyses. JD, NH, AG, BT, and JATdS analyzed the data and co-wrote all versions of the paper. JD, NH, AG, BT, and JATdS take responsibility for the content of the paper.

Funding Information Open access funding provided by University of Debrecen (DE). The research was financed by the Higher Education Institutional Excellence Programme (NKFIH-1150-6/2019) of the Ministry of Innovation and Technology in Hungary, within the framework of the Biotechnology Thematic Programme of the University of Debrecen. The study and submission for publication was approved by the University of Debrecen (BPTR/DEENK/0007/2019).

Data Availability The raw Illumina mRNA-seq data were submitted to NCBI, and the processed data were deposited under GEO ID GSE135294, BioProject ID PRJNA558262, and SRA ID SRP217133 for the 10 samples: GSM4002842, GSM4002843, GSM4002844, GSM4002845, GSM4002846, GSM4002847, GSM4002848, GSM4002849, GSM4002850, and GSM4002851.

\section{Compliance with Ethical Standards}

Conflict of Interest The authors declare that they have no conflicts of interest.

Open Access This article is licensed under a Creative Commons Attribution 4.0 International License, which permits use, sharing, adaptation, distribution and reproduction in any medium or format, as long as you give appropriate credit to the original author(s) and the source, provide a link to the Creative Commons licence, and indicate if changes were made. The images or other third party material in this article are included in the article's Creative Commons licence, unless indicated otherwise in a credit line to the material. If material is not included in the article's Creative Commons licence and your intended use is not permitted by statutory regulation or exceeds the permitted use, you will need to obtain permission directly from the copyright holder. To view a copy of this licence, visit http://creativecommons.org/licenses/by/4.0/.

\section{References}

Andersen CL, Jensen JL, Ørntoft TF (2004) Normalization of real-time quantitative reverse transcription-PCR data: a model-based variance estimation approach to identify genes suited for normalization, applied to bladder and colon cancer data sets. Cancer Res 64(15): 5245-5250. https://doi.org/10.1158/0008-5472.CAN-04-0496
Dobránszki J, Mendler-Drienyovszki N (2014) Cytokinin-induced changes in the chlorophyll content and fluorescence of in vitro apple leaves. J Plant Physiol 171:1472-1478. https://doi.org/10.1016/j. jplph.2014.06.015

Dobránszki J, Asboth G, Homoki D, Bíró-Molnár P, Teixeira da Silva JA, Remenyik J (2017) Ultrasonication of in vitro potato single node explants: activation and recovery of antioxidant defence system and growth responses. Plant Physiol Biochem 121:153-160. https://doi.org/10.1016/j.plaphy.2017.10.022

Dobránszki J, Hidvégi N, Gulyás A, Teixeira da Silva JA (2019) mRNA transcription profile of potato (Solanum tuberosum L.) exposed to ultrasound during different stages of in vitro plantlet development. Plant Mol Biol 100(4-5):511-525. https://doi.org/10.1007/s11103019-00876-0

Ghosh R, Mishra RC, Choi B, Kwon YS, Bae DW, Park SC, Jeong MJ, Bae H (2016) Exposure to sound vibrations lead to transcriptomic, proteomic and hormonal changes in Arabidopsis. Sci Rep 6:33370 33317. https://doi.org/10.1038/srep33370

Götz S, García-Gómez JM, Terol J, Williams TD, Nagaraj SH, Nueda MJ, Robles M, Talón M, Dopazo J, Conesa A (2008) Highthroughput functional annotation and data mining with the Blast2GO suite. Nucleic Acids Res 36(10):3420-3435. https://doi. org/10.1093/nar/gkn176

Guo M, Liu JH, Ma X, Luo DX, Gong ZH, Lu MH (2016) The plant heat stress transcription factors (HSFs): structure, regulation, and function in response to abiotic stresses. Front Plant Sci 7:114. https://doi. org/10.3389/fpls.2016.00114

Hildebrandt TM, Nesi AN, Araújo WL, Braun HP (2015) Amino acid catabolism in plants. Mol Plant 8:264-276. https://doi.org/10.1016/ j.molp.2015.09.005

Kanehisa M, Furumichi M, Tanabe M, Sato Y, Morishima K (2017) KEGG: new perspectives on genomes, pathways, diseases and drugs. Nucleic Acids Res 45:D353-D361. https://doi.org/10.1093/ nar/gkw1092

Kaur H, Mukherjee S, Baluska F, Bhatla SC (2015) Regulatory roles of serotonin and melatonin in abiotic stress tolerance in plants. Plant Signal Behav 10(11):e1049788. https://doi.org/10.1080/15592324. 2015.1049788

Kim D, Langmead B, Salzberg SL (2015) HISAT: a fast spliced aligner with low memory requirements. Nat Methods 12(4):357-360. https://doi.org/10.1038/nmeth.3317

Liu J, Pang X, Cheng Y, Yin Y, Zhang Q, Su W, Hu B, Guo Q, Ha S, Zhang J, Wan H (2018) The Hsp70 gene family in Solanum tuberosum: genome-wide identification, phylogeny, and expression patterns. Sci Rep 8:16628-16611. https://doi.org/10.1038/s41598018-34878-7

Mishra D, Shekhar S, Singh D, Chakraborty S, Chakraborty N (2018) Heat shock proteins and abiotic stress tolerance in plants. In: Asea A, Kaur P (eds) Regulation of heat shock protein responses, heat. Springer International Publishing AG, pp 41-69. https://doi.org/10. 1007/978-3-319-74715-6 3

Müller M, Munné-Bosch S (2015) Ethylene response factors: a key regulatory hub in hormone and stress signaling. Plant Physiol 169(1): 32-41. https://doi.org/10.1104/pp.15.00677

Murashige T, Skoog F (1962) A revised medium for rapid growth and bio assays with tobacco tissue cultures. Physiol Plant 15(3):473-497. https://doi.org/10.1111/j.1399-3054.1962.tb08052.x

Pfaffl MW, Tichopad A, Prgomet C, Neuvians TP (2004) Determination of stable housekeeping genes, differentially regulated target genes and sample integrity: BestKeeper-excel-based tool using pair-wise correlations. Biotechnol Lett 26(6):509-515. https://doi.org/10. 1023/B:BILE.0000019559.84305.47

Rawat R, Schwartz J, Jones MA, Sairanen I, Cheng Y, Andersson CR, Zhao Y, Ljung K, Harmer SL (2009) REVEILLE1, a Myb-like transcription factor, integrates the circadian clock and auxin 
pathways. Proc Natl Acad Sci U S A 106(39):16883-16888. https:// doi.org/10.1073/pnas.0813035106

Rokhina EV, Lens P, Virkutyte J (2009) Low-frequency ultrasound in biotechnology: state of the art. Trends Biotechnol 27(5):298-306. https://doi.org/10.1016/j.tibtech.2009.02.001

Safari M, Ghanati F, Behmanesh M, Hajnorouzi A, Nahidian B, Mina G (2013) Enhancement of antioxidant enzymes activity and expression of CAT and PAL genes in hazel (Corylus avellana L.) cells in response to low-intensity ultrasound. Acta Physiol Plant 35(9):28472855. https://doi.org/10.1007/s11738-013-1318-6

Savatin DV, Gramegna G, Modesti V, Cervone F (2014) Wounding in the plant tissue: the defense of a dangerous passage. Front Plant Sci 5: 470. https://doi.org/10.3389/fpls.2014.00470

Sazegari S, Niazi A, Ahmadi FS (2015) A study on the regulatory network with promoter analysis for Arabidopsis DREB-genes. Bioinformation 11(2):101-106. https://doi.org/10.6026/ 97320630011101

Tang X, Zhang N, Si H, Calderón-Urrea A (2017) Selection and validation of reference genes for RT-qPCR analysis in potato under abiotic stress. Plant Methods 13(1):85. https://doi.org/10.1186/s13007-017-0238-7

Teixeira da Silva JA, Dobránszki J (2014) Sonication and ultrasound: impact on plant growth and development. Plant Cell Tissue Organ Cult 117:131-143. https://doi.org/10.1007/s11240-014-0429-0

Teixeira da Silva JA, Hidvégi N, Gulyás A, Dobránszki J (2019) mRNA transcription profile of potato (Solanum tuberosum L.) in response to explant cutting. Plant Cell Tissue Organ Cult 138(1):143-152. https://doi.org/10.1007/s11240-019-01613-7

Vandesompele J, De Preter K, Pattyn F, Poppe B, Van Roy N, De Paepe A, Speleman F (2002) Accurate normalization of real-time quantitative RT-PCR data by geometric averaging of multiple internal control genes. Genome Biol 3(7):research0034-1. https://doi.org/ 10.1186/gb-2002-3-7-research0034

Wang W, Vinocur B, Shoseyov O, Altman A (2004) Role of plant heatshock proteins and molecular chaperones in the abiotic stress response. Trends Plant Sci 9(5):244-252. https://doi.org/10.1016/j. tplants.2004.03.006

Wang BC, Zhou J, Wang YC, Zhu LC, Teixeira da Silva JA (2006) Physical stress and plant growth. In: Teixeira da Silva J (ed) Floriculture, ornamental and plant biotechnology: advances and topical issues, vol II, 1st edn. Global Science Books, Ltd, Isleworth, Chapter 7, pp 68-85

Xie F, Xiao P, Chen D, Xu L, Zhang B (2012) miRDeepFinder: a miRNA analysis tool for deep sequencing of plant small RNAs. Plant Mol Biol 80(1):75-84. https://doi.org/10.1007/s11103-012-9885-2

Publisher's Note Springer Nature remains neutral with regard to jurisdictional claims in published maps and institutional affiliations. 